\title{
Feasibility Study of Cauliflower in Hot region of Sri Lanka and Their post-Harvest Losses
}

\author{
M.P.M. Irshath ${ }^{1}$ A.B.M. Jesfar ${ }^{2}$ \\ irshathmohh@gmail.com \\ ${ }^{1}$ Ex.Department of Agriculture, Eastern Province, Segment office, Samanturai, Sri Lanka \\ ${ }^{2}$ Department of Agriculture, Hardy Advanced Technological Institute, SLIATE, Ampara, Sri \\ Lanka
}

\section{Abstract}

Vegetable takes major role in Sri Lankan economy. Among the different vegetable cultivation in Sri Lanka cauliflower is a high value vegetable. Anyhow it's cultivation is restricted to cool climate conditions particularly in Nuwereliya district of Sri Lanka.

Hence this feasibility study was conducted to identify the suitability of crop establishment in hot region of Sri Lanka in Dodangwella University farm at kundasala. Four varieties of cauliflower such as 45 days variety, Early phenominal, Frenchi and P-103 were systematically established under the Agriculture department's recommendations and Agronomy practices. Vegetable and reproductive characters such as germination period, germination percentage, plant growth rate, leaf production, time for curd formation. Curd development, curd color, time for maturity and yield were evaluated respectively.

Randomized Complete Block Design was used to arrange the field establishment and Minitab was used to analyze the vegetative and reproductive characters of four varieties of cauliflowers. The results revealed that except Frenchi other varities were played well performance in germination and nursery evaluation stages. Particularly P-103 verity was played very significant in relation to vegetative characters. But, Frenchi variety show very low significant in all vegetative characters except leaf area. Further, it is found to be that curd formation was developed only in 45 days variety with poor yield. But keeping quality was satisfactory.

Keywords: Cauliflower, Feasibility study, Vegetative and reproductive stages, Plant growth, Germination percentage, quality 


\subsection{INTRODUCTIONS:}

\section{Background and Justification}

Cauliflower (Brassica olearaceae) is a valuable vegetable among other vegetables. It belongs to the family Cruciferae. Cauliflower has it origin in the Mediterranean region. But it is now distributed Europe, USA and many tropical areas such as India, Malaysia, Philippines, Central, and east West Africa. High land areas of many tropical regions are the main areas of this cultivation. It is a biennial crop but grown as an annual crop. There are many varities area available. Particularly in Asia, Afghani, Early Benares, Early market, Early Patna, Early snowball, Kunwari, Poopsi and Snow Peak are the most suitable varities. About Rs 0.37Mn is contributing in Sri Lanka yearly. But it was drastically reduced in year 1996-1998 due to the lower production in the cultivation area. It was due to the lack of land area having suitable climatic condition. Hence, the cultivation should be adopted to the high land available area and hot region of Sri Lanka.

Objectives:

01. To study the feasibility of Cauliflower cultivation in hot region of Sri Lanka.

02. To find the suitability of the hot region for cauliflower cultivation in Sri Lanka.

\subsection{LITERATURE REVIEW}

Cauliflower thrives best in cool and moist climate. Cauliflower withstands so low temperature or so much heat as cabbage does. Dry weather and low humidity re not subtle from it.For good seed germination, temperature of 50 to 70 faranite is required. High temperature produce poor quality curds viz ricey, leafy, fuzzy loose and yellow curds. Temperature below the optimum during growing period delays the maturity and undersized small unmarketable curds or buttons may be formed. Dry hot weather may give to rice to small hard curds. It can be grown in wide range soil provided they are rich in nutrient and have adequate soil moisture, possess good drainage and also contain plenty of organic matter, sandy loamy soil are preferred preferred for early corps while loam and clay loams for late crops. Cauliflower grow best to neutral to acid soil i.e., at $\mathrm{pH}$ 6.0 to 7.00.If the soil is blow pH 5.5 liming at the rate of 5 to $10 \mathrm{q} / \mathrm{ha}$ should be done for successful raising of cauliflower.(Ariya, R.L. Sonam Ariya , Renu Ariya, 2020)

Fairly deep, loamy soil is also desired sandy loams and silt loams are preferred, while good clay loams $r$ used. Good drainage is practically important where the crop is grown during the fall or in the winter (Thompson and Kelly, 1959).Soil should be well provided with good moisture retention properties of the soil. 
Cauliflower is harvested when the heads attain the proper size and before and before they begin to rice and become discolored. Medium sized heads have the greatest demand (Thomson and Kelly, 1959). The suitable size is usually six inches or more in diameter. Head should be harvested before they are over mature and the flower parts are separated (Waltere. Spilittifosser, 1979).The harvesting is done either in the evening or early in the morning. Curds of cauliflower can be harvested at 120 days from transplanting, depending on the cultivar growth (Tindall, 1983).

There are many activities involved to minimize the post-harvest losses during harvesting, packing, storing and handling.(Walter, E. Splitstoesser, 1979) state that heads are harvested by cutting the main stem and ( Thompson and Katyal, S.L, 1985) report that the total stem cut is about $25 \mathrm{~cm}$. The axillary shoots, as they develop, are cut at the same stage as the central heads. Further, cauliflower is not ordinarily stored, but good sound heads can be kept for a short period in cold storage. Good cauliflower can be kept for at least 30 days in cold storage at $32^{0} \mathrm{~F}$ ( Jamision \& Thompson, 1934). (Lee \& carols, 1949) has found that treating cauliflower with Naphthalene acetic acid or 2,4,D prevents leaf abscission and increase the length of storage life.

\subsection{METHODS AND MATERIALS}

The experiment was conducted at the Dodangwella research station of University of Peradeniya at Kundasala in August, 2000. This station is located 18km away from university to the north direction in the central province of Sri Lanka. The location belongs to Inter Mediate - 3 agro ecological zone. Soil type was RBE with a texture of sandy clay loam. The slope was gentle and it was not subjected to cauliflower cultivation in previous period. The experiment site receive $264 \mathrm{~mm}$ mean rain fall. The minimum and maximum temperature was recorded as 26 degree Celsius and 30 respectively.

Four verities of cauliflower such as 45 days, early Phenomenal, Frnchi and P-03 were separately developed in raised sized $1 \mathrm{~m}$ X5m beds with $10 \mathrm{~cm}$ depth. All five nursery beds were fumigated with captain and closed for three days by polythene. Seeds were directly sown on top soil layer. Watering was done soon after sowing the seeds. Black net was used to protect seedling from sun scorching. Watering, weed control, thinning out, pest and disease management was conducted according to the Sri Lanka Agriculture departmental recommendations.

Two ploughing and one harrowing were done using tractor to $40 \mathrm{cn}$ depth. Cow dung was incorporated and the land kept for five days. Plant holes were made $45 \mathrm{~cm}$ part and it was incorporated with cow dung and adequate amount of dolomite. It was practiced for maintain the $\mathrm{pH}$ up to 7-7.2. Also top dressing was applied then holes were leaved for five days for incorporation of organic matter. Different varieties were planted in different spacing as follow below, 
Table 1.0 Spacing for different cauliflower varities

\begin{tabular}{lcc}
\hline \multicolumn{1}{c}{ Verities } & \multicolumn{2}{c}{ Planting space } \\
\cline { 2 - 3 } 45 Day & Inter raw & Intra raw \\
Early phenomenal & $50 \mathrm{~cm}$ & $50 \mathrm{~cm}$ \\
Frenchi & $60 \mathrm{~cm}$ & $60 \mathrm{~cm}$ \\
P-103 & $60 \mathrm{~cm}$ & $60 \mathrm{~cm}$ \\
\hline
\end{tabular}

Uniform seedling were selected from nursery planted in the middle of hole.it was covered using albeit to reduce the evaporation from the leaves. Early morning watering was practiced using watering cane to reduce the mechanical damage. Also manual weeding was done after one week and it was continue in the late stage using mamotty. The field was subjected to insecticide and fungal attack again leaf eating caterpillar and color rot fungus disease. Earthling up is conducted from ten days trans planting up to harvesting stage.

Randomized complete block designs was used with four replicates. Replicates represented about twenty plants for the all varieties.

\subsection{RESULTS AND DISCUSSION}

\subsection{Leaf area}

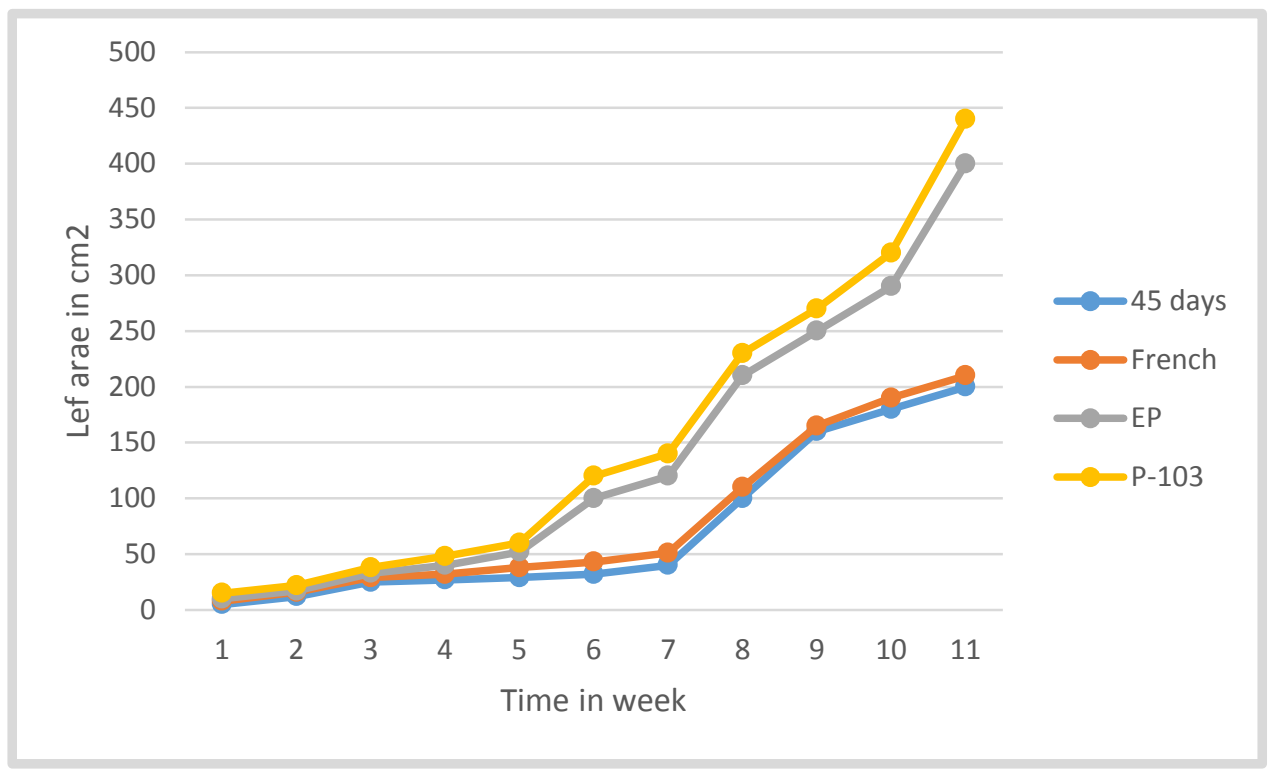

Graph 4.1 The relationship between leaf arae and time after planting 
The results implies that EP and P-103 were played higher leaf are than Frenchi and 45 days varieties. Those also showed rapid incensement leaf area in in between $1^{\text {st }}-11^{\text {th }}$ weeks of whole period. But Frenchi and 45 days verities were followed the same until $2^{\text {nd }}$ week of vegetative stage whereas they showed lower incensement rate than P-103 and EP from $7^{\text {th }}$ to $11^{\text {th }}$ week. Anyhow all verities played uniform leaf area increment rate. 


\subsection{Plant growth rate Vs week}

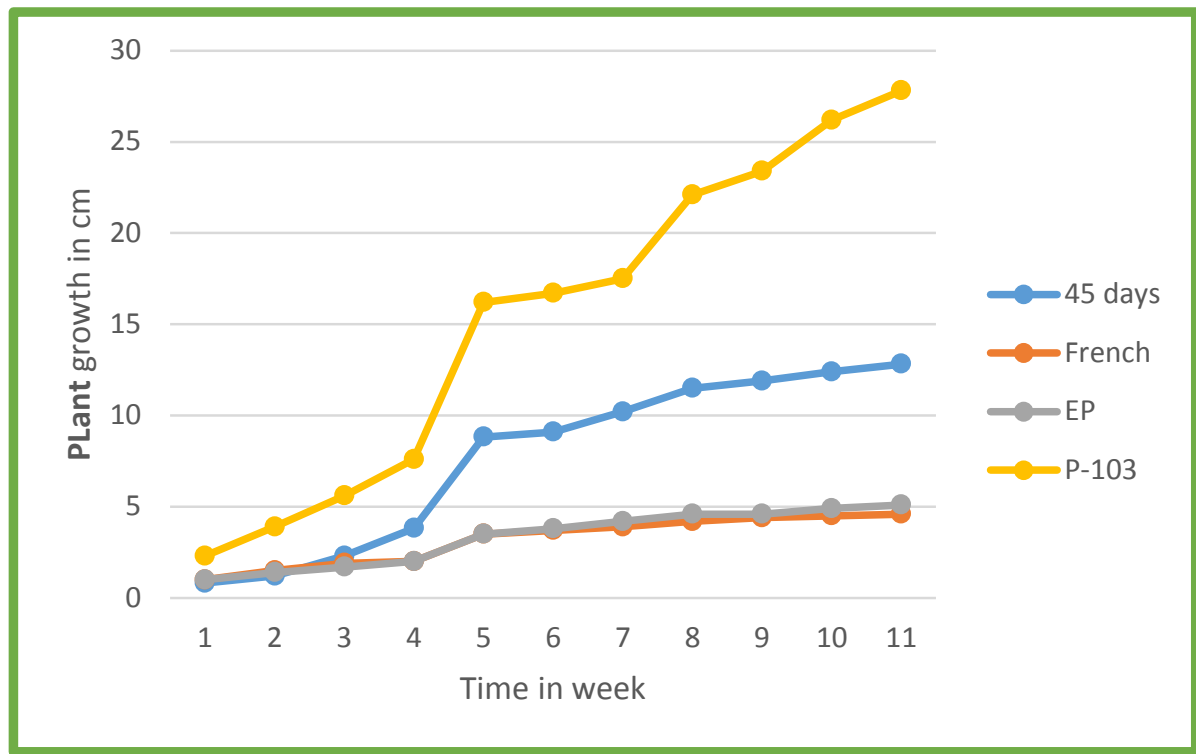

Graph 4.2 The relationship between plant growth and time after planting

EP and P-103 showed higher growth rate than 45 days variety and Frenchy. It played smooth rate until $5^{\text {th }}$ week then it was increased rapidly until $11^{\text {th }}$ week. But 45 Days and Frenchy verities were followed uniform growth rate until $7^{\text {th }}$ week then it was continued rapid rate until $11^{\text {th }}$ weeks. 


\section{Plant leaf productions Vs leaf production}

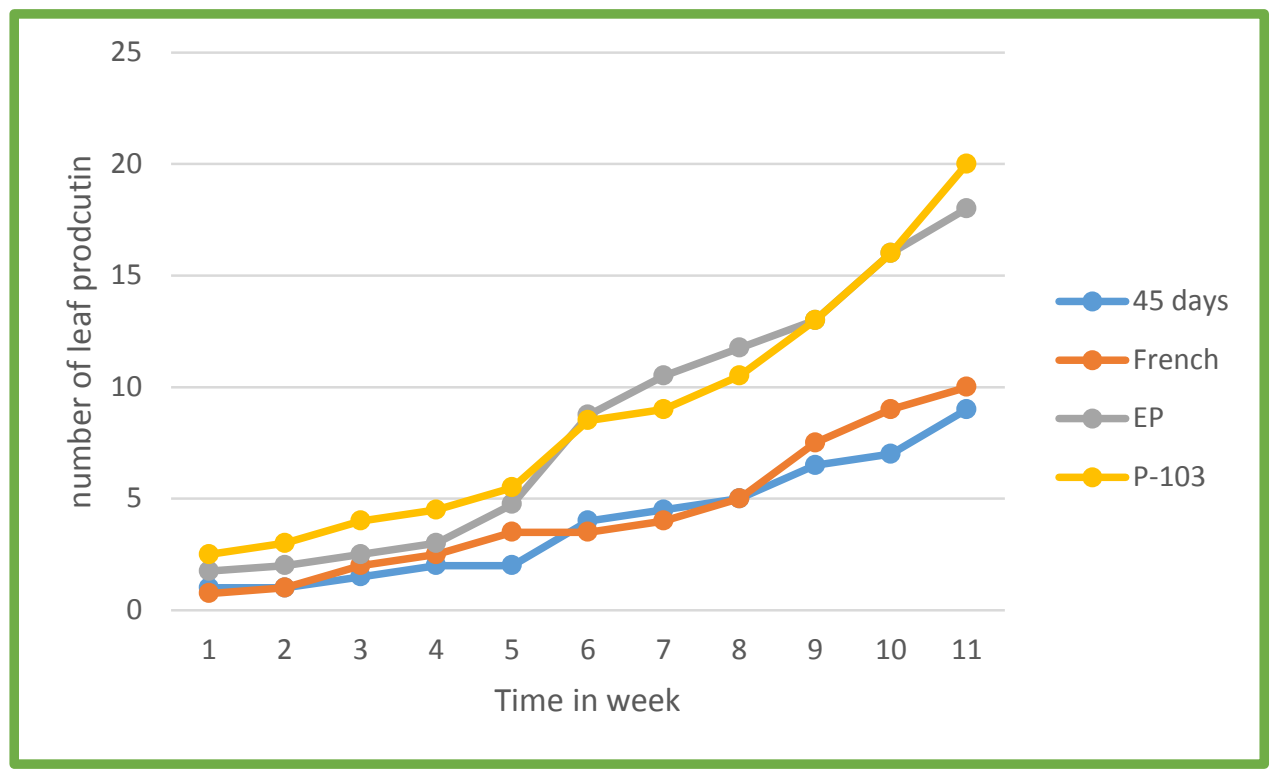

Graph 4.3 The relationship between leaf arae rodcution and time after planting

EP and P-103 showed greater leaf production than 45days and Frenchy verities up to $11^{\text {th }}$ week of plant production. Also those varieties played rapid rate increment after $6^{\text {th }}$ week and it was continued up to $11^{\text {th }}$ week of production. Anyhow 45 days and Frenchy varieties were followed uniform growth rate incensement.

\subsection{CONCLUSIONS}

During the period of nursery evaluation, all four varieties performed well, however poor germination was in French verity. In vegetative stage, P-103 variety was significant in all vegetative characters, whereas French had low significant except in it's leaf area. In the reproductive stage, curd formation was observed only in 45 days variety with poor curd development and low yield. But keeping quality was satisfactory. Comparatively, P-103 was very significant in all vegetable stage than other varieties. 


\section{REFERENCES}

[1] Thompson and Kelly, 1957.Vegetable crops, New York, (18):295-306.

[2] Tindal, H. D., 1983, Vegetable in the tropic, cauliflower. Hong Kong. Pp: 118-120.

[3] Walter, E. Splittstoesser, 1979, Vegetable growing hand book, Cauliflower. United states of America.pp:189-191.

[4] Ariya, R.L. Sonam Ariya. Renu Ariya, 2020, Fundamental of Agriculture, Volume 2, pp:131.

[5] Thompson and Kelly, 1957, vegetable crops, Cole crops, New York, (18): 295-306. 